\title{
COMPORTAMENTO REOLÓGICO, MECÂNICO, TERMOMECÂNICO E MORFOLÓGICO DE BLENDAS DE POLIESTIRENO/RESÍDUO DE CALÇADOS COM DIFERENTES GRANULOMETRIAS
}

\author{
Carlos Bruno Barreto Luna ' \\ Divânia Ferreira da Silva ' \\ Edcleide Maria Araújo ' \\ Tomás Jeferson Alves de Mélo ${ }^{\prime}$ \\ Amanda Dantas de Oliveira ${ }^{2}$
}

\section{Resumo}

O objetivo deste trabalho foi produzir blendas poliméricas a partir de uma matriz de poliestireno (PS) com resíduos de borracha de calçados (SBRr), visando avaliar a influência da granulometria e o efeito do compatibilizante estireno-butadieno-estireno (SBS) nas propriedades reológicas, mecânicas (impacto e flexão), temperatura de deflexão térmica (HDT) e na morfologia. As blendas de poliestireno/resíduos de borracha foram preparadas em uma extrusora de rosca dupla corrotacional e, posteriormente, moldadas por injeção. A blenda PS/SBRr/SBS (40 mesh) teve um aumento de $254 \%$ na resistência ao impacto em relação ao poliestireno, bem como uma perda de apenas $10 \%$ no valor de sua rigidez sob flexão. Os valores da HDT das blendas diminuíram em relação à matriz de poliestireno. As curvas de reologia das blendas praticamente não apresentaram mudanças significativas. As fotomicrografias das blendas compatibilizadas evidenciaram uma morfologia característica de blendas imiscíveis. Considerando todas as dificuldades inerentes para reaproveitar os resíduos de borracha, os resultados evidenciam que é possível obter um material com boas propriedades, bem como reduzir custos no desenvolvimento de um novo material.

Palavras-chave: Blendas poliméricas; Resíduos de borracha; Compatibilizante; Granulometria.

\section{RHEOLOGICAL, MECHANICAL, THERMOMECHANICAL AND MORPHOLOGICAL BEHAVIOR OF POLYSTYRENE/SHOES RESIDUE BLENDS WITH DIFFERENT GRANULOMETRY}

\begin{abstract}
The aim of this work was to produce polymer blends from a polystyrene (PS) matrix with shoes rubber waste (SBRr), to evaluate the influence of granulometry and the effect of styrene-butadiene-styrene (SBS) compatibilizer on rheological, mechanical (impact and flexion), heat deflection temperature (HDT) and morphology. The blends of polystyrene/rubber waste were prepared in a twin-screw co-rotational extruder and then injection moulded. The blend of PS/SBRr/SBS (40 mesh) had a $254 \%$ increase in impact strength in relation to polystyrene, as well as a loss of only 10\% in its rigidity under flexion. The values of the HDT of the blend decreased compared to the polystyrene matrix. The rheology curves of the blends had no significant changes. The photomicrographs of compatibilized blends showed a characteristic morphology of immiscible polymer blends. Considering all the inherent difficulties to recycle rubber waste, the results show that it is possible to obtain a material with good properties and reduce costs in the development of a new material.

Keywords: Polymer blends; Rubber residue; Compatibilizer; Granulometry.
\end{abstract}

'Universidade Federal de Campina Grande - UFCG, Campina Grande, PB, Brasil. E-mail: brunobarretodemaufcg@hotmail.com

${ }^{2}$ Centro de Desenvolvimento Tecnológico-Engenharia de Materiais, Universidade Federal de Pelotas - UFPel, Pelotas, RS, Brasil.

2176-1523 (C) 2016 Associação Brasileira de Metalurgia, Materiais e Mineração. Publicado pela ABM. Este é um artigo de acesso aberto distribuído sob os termos da licença Creative Commons CC BY-NC-ND (Attribution-NonCommercial-NoDerivs) - https:// creativecommons.org/licenses/by-nc-nd/4.0\%. 


\section{INTRODUÇÃO}

Nos últimos anos a prática da reciclagem tem sido incentivada em um esforço para aumentar a conscientização sobre as questões ambientais, devido a grande quantidade de resíduos gerados nos processos de fabricações, e consequentemente promover a redução dos recursos utilizados [I]. Atualmente, destaca-se o crescente consumo de materiais à base de polímeros, impulsionado pela diversidade de propriedades e características. Porém, um dos principais materiais poliméricos nocivos ao meio ambiente é a borracha sintética [2]. Os resíduos de borracha sintética são fonte de poluição ambiental e desperdício de matéria-prima com boas propriedades. Sabe-se que estes materiais apresentam resistência relativamente alta a agentes biológicos e às intempéries, causando assim sérios problemas aos ecossistemas. Portanto, tanto os aspectos econômicos quanto a minimização dos impactos ambientais são justificativas no sentido de promover a reciclagem destes materiais poliméricos [3]. Entretanto, por possuírem uma estrutura reticulada, esses materiais não podem ser fundidos e remoldados como os termoplásticos, dificultando o seu reaproveitamento [4]. Uma das alternativas para o reaproveitamento desses resíduos é por meio da mistura física com termoplásticos, ou seja, o desenvolvimento de blendas poliméricas. Dessa forma, os resíduos dispersam-se na matriz termoplástica durante o processamento, atuando como cargas [5].

A mistura de dois ou mais polímeros torna possível à combinação de várias propriedades no material, geralmente de forma mais econômica que no caso da síntese de novos polímeros. $O$ uso do pó de borracha em misturas com termoplásticos tem ampla aplicação tecnológica e científica, porque é possível produzir novos materiais com facilidade de processamento e boas propriedades elásticas. Entretanto, devido às diferenças estruturais e de viscosidade, a simples adição dos dois compostos não produz um novo material com sinergismo de propriedades. Neste caso, é frequente $o$ uso de um compatibilizante para melhorar $\circ$ desempenho da mistura [6]. O compatibilizante geralmente se aloja na interface entre os dois polímeros (Figura I), desempenhando as funções de: melhorar a adesão interfacial, estabilizar a morfologia e diminuir a tensão interfacial [8].

Alguns trabalhos já foram relatados na literatura sobre o desenvolvimento de misturas poliméricas a base de resíduos de borracha e termoplásticos.

Zhao et al. [9] produziram elastômeros termoplásticos (TPE) baseados em blendas de poliestireno de alto impacto (HIPS)/resíduo de borracha de estireno-butadieno em pó (WSBRP). As blendas foram preparadas por mistura mecânica e reforçadas com incorporação do copolímero em bloco de estireno-butadieno-estireno (SBS) e óleo aromático (AO). O efeito do teor de SBS e AO sobre as propriedades mecânicas e morfológicas das misturas foram investigadas. Os resultados mostraram que a incorporação de SBS e AO na blenda HIPS/WSBRP melhorou as propriedades mecânicas de forma significativa. A mistura HIPS/WSBRP teve um aumento de $220 \%$ no alongamento na ruptura para a composição contendo 9 pcr (partes por cem de resina) de SBS e 15 pcr de AO.

Gopalakrishnan e Kutty [10] prepararam misturas de poliestireno (PS)/borracha natural (NR) na proporção de $85 / 15 \%$ curadas dinamicamente por fusão em um misturador interno a $170^{\circ} \mathrm{C}$ utilizando peróxido de dicumila (DCP). A concentração de DCP foi variada de 0 a 4,2 miliequivalentes (meq). Verificou-se que a cura da mistura com 2,8 meq de DCP aumentou significativamente o módulo de Young, módulo de flexão e resistência ao impacto, com uma melhoria na tração e resistência à flexão. Os estudos por MEV revelaram que a morfologia das blendas mudou drasticamente com a cura dinâmica. Os estudos de reologia revelaram que o amortecimento da mistura foi reduzido nas condições de processamento por fusão, com um teor de 2,8 meq de DCP. A estabilidade térmica da mistura com a cura dinâmica foi melhorada. Assim, a cura dinâmica pode ser utilizada como uma técnica de compatibilização tecnológica para a mistura PS/NR (85/I5) melhorando suas propriedades.

Luna et al. [ I I] desenvolveram blendas de poliamida 6/resíduo de borracha reciclada (SBRr), com adição de um agente compatibilizante (PE-g-MA). As blendas, inicialmente foram preparadas em uma extrusora de rosca dupla corrotacional e, posteriormente, os grânulos extrusados foram moldados por injeção. As blendas de PA6/SBRr e $\mathrm{PA} 6 / \mathrm{SBRr} / \mathrm{compatibilizante}$ foram analisadas por meio de ensaios de temperatura de deflexão térmica (HDT), análise térmica dinâmico-mecânica (DMTA), calorimetria exploratória diferencial (DSC) e mecânico (impacto). Ficou evidenciado que a resistência ao impacto e a temperatura de deflexão térmica das blendas reduziram pouco quando comparadas com a poliamida 6. No ensaio de DMTA para as blendas binárias e ternárias houve deslocamento dos picos para aproximadamente $-10^{\circ} \mathrm{C}$ e o deslocamento da relaxação $\alpha$ da PA6 para valores maiores. Para a DSC em todas as

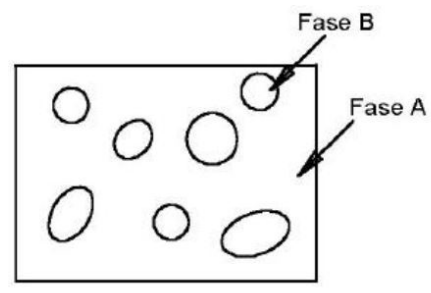

(a)
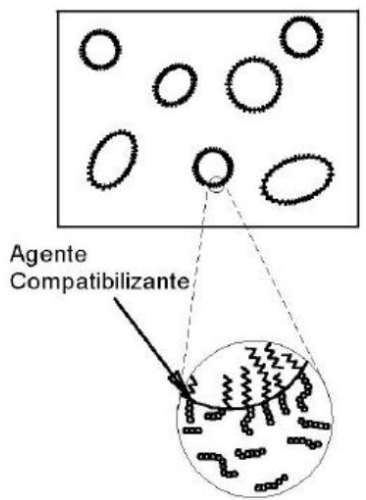

(b)

Figura I. Esquema representativo de blendas (a) sem compatibilizante e (b) compatibilizada. Fonte: Becker [7]. 
curvas observa-se a presença dos picos da temperatura de cristalização da PA6 tanto para as blendas binárias quanto para as ternárias.

Uma das utilizações mais empregadas de elastômeros em blendas é a de promover a tenacificação de polímeros frágeis (Exemplo: PMMA, PS, etc), ou seja, melhorar o desempenho da resistência ao impacto. Entretanto, a incorporação de resíduo de borracha em uma matriz polimérica frágil pode ser influenciada por vários fatores, tais como: granulometria da borracha, tipo de óleo utilizado, quantidade de borracha adicionada, teor de negro de fumo na borracha, tipo de termoplástico, adesão entre a matriz e a borracha moída, modificação da sequência de mistura e o tipo de compatibilizante [12,13]. Portanto, a escolha adequada dos parâmetros pode otimizar as propriedades do material.

O presente trabalho tem como objetivo estudar o efeito do compatibilizante SBS (estireno-butadieno-estireno) e da granulometria no desenvolvimento de blendas de poliestireno/resíduo de borracha da indústria de calçado, visando a obtenção de materiais com propriedades superiores ao poliestireno.

\section{MATERIAIS E MÉTODOS}

\section{I Materiais}

Como matriz polimérica foi utilizada o poliestireno cristal (PS) sob o código I58K Q6II, IF= 4,5 g/I0 min na forma de grânulos, fabricado pela Unigel S.A. Foi utilizado como fase dispersa um resíduo de borracha ( $\mathrm{SBRr}$ ), proveniente da indústria de calçados São Paulo Alpargatas S.A., fabricante das sandálias Havaianas, da região de Campina Grande/PB. A formulação do composto é baseada em: cargas minerais, elastômero de butadieno e estireno, pigmentos, acelerantes, esponjantes, agentes de fluxo e agente de vulcanização. A composição parcial aproximada do resíduo é: $31 \%$ de SBR, $26,8 \%$ de $\mathrm{CaCO}_{3}, 21,5 \%$ de óleo, $7 \%$ de negro de fumo e $13,7 \%$ de massa residual. Como agente compatibilizante foi utilizado o copolímero tribloco linear SBS (estireno-butadieno-estireno), sob o código Kraton DI IOIB, a base de estireno e butadieno contendo $31 \%$ de poliestireno, na forma de grânulos, adquirido da Activas S.A.

\subsection{Métodos}

\subsection{Preparação das blendas}

Antes da preparação das blendas, o resíduo de borracha advindo da indústria foi peneirado em duas peneiras com malhas de 40 mesh $(0,420 \mathrm{~mm})$ e 18 mesh ( $\mathrm{lmm}$ ), respectivamente. As blendas binárias PS/SBRr foram preparadas nas proporções de $50 / 50 \%$ em massa e as ternárias $\mathrm{PS} / \mathrm{SBRr} / \mathrm{SBS}$ nas proporções de 47,5/47,5/5\% em massa. O poliestireno puro e as blendas foram processados em uma extrusora de rosca dupla corrotacional modular, modelo ZSK ( $D=18 \mathrm{~mm}$ e L/D = 40), da Coperion ZSK, com temperatura de $190^{\circ} \mathrm{C}$ nas zonas I e 2 , e $200^{\circ} \mathrm{C}$ nas demais zonas, velocidade de rotação da rosca de $250 \mathrm{rpm}$ e taxa de alimentação controlada de $4 \mathrm{~kg} / \mathrm{h}$, com perfil de rosca configurado com elementos de mistura distributivo e dispersivo. Os grânulos extrudados foram secos, em uma estufa a vácuo com temperatura de $60^{\circ} \mathrm{C}$ durante 48 horas. Após a secagem, os grânulos extrudados foram moldados por injeção na forma de corpos de prova para ensaios de impacto lzod (ASTM D256), flexão (ASTM 790) e HDT (ASTM D648). Os corpos de prova foram moldados em uma injetora Fluidmec, na temperatura de $180^{\circ} \mathrm{C}$ na zona I e $190^{\circ} \mathrm{C}$ na zona 2 , temperatura do molde de $20^{\circ} \mathrm{C}$ e ciclo de injeção de 25 s.

\subsection{Caracterização das Blendas}

\subsection{Reometria de torque}

O ensaio de reometria de torque foi realizado em um misturador interno RHEOMIX 600, acoplado a um reômetro de torque System 90 da Haake Büchler, operando com rotores do tipo roller, a uma velocidade de rotação de $50 \mathrm{rpm}$, temperatura de $200^{\circ} \mathrm{C}$ durante 10 minutos em atmosfera de ar. A massa total dentro da câmara de mistura foi mantida constante em $55 \mathrm{~g}$ para todas as composições.

\subsubsection{Ensaio de impacto}

O ensaio sob impacto Izod foi realizado em 10 corpos de prova entalhados segundo a norma ASTM D256, em um aparelho da marca Ceast modelo Resil 5,5 J, operando com martelo de 2,75 J em temperatura ambiente.

\subsubsection{Ensaio sob flexão}

Os testes sob flexão foram conduzidos em uma máquina universal de ensaios da Shimadzu com capacidade de $50 \mathrm{kN}$, segundo a norma ASTM D790, operando em modo de compressão a uma velocidade de $1,6 \mathrm{~mm} / \mathrm{min}$ e separação entre os apoios de $64 \mathrm{~mm}$. Os resultados foram analisados com uma média de 6 corpos de prova.

\subsubsection{Temperatura de deflexão térmica (HDT)}

A temperatura de deflexão térmica (HDT) foi obtida, conforme a norma ASTM D648, em um equipamento Ceast, modelo HDT 6 VICAT, com uma tensão de I,82 MPa, taxa de aquecimento de $120^{\circ} \mathrm{C} / \mathrm{h}$ (método $\mathrm{A}$ ). A temperatura foi determinada após a amostra ter defletido $0,25 \mathrm{~mm}$. Os resultados foram analisados com uma média de 3 corpos de prova. 


\subsubsection{Microscopia eletrônica de varredura (MEV)}

As análises por microscopia eletrônica de varredura (MEV) foram realizadas na superfície de fratura dos corpos de prova submetidos ao ensaio de impacto. Foi utilizado um microscópio eletrônico de varredura, Shimadzu SSX-550 Superscan, a uma voltagem de $15 \mathrm{kV}$, sob alto vácuo e as superfícies de fratura dos corpos de prova foram recobertas com ouro.

\section{RESULTADOS E DISCUSSÃO}

\section{I Reometria de Torque}

A Figura 2 apresenta as curvas de variação do torque em função do tempo para as amostras de PS, blendas sem e com compatibilizante com as diferentes granulometrias de resíduos, respectivamente.

Conforme a Figura 2a nota-se que após 2 min de processo, o torque tende a ficar praticamente constante, com pequenas oscilações em torno de um valor médio. Este comportamento indica estabilidade da viscosidade para as condições de processo utilizadas, ou seja, velocidade de $50 \mathrm{rpm}$ e temperatura de $200^{\circ} \mathrm{C}$. Observa-se que os valores de torques finais ou após 10 min de mistura das blendas binárias, independente da granulometria do $\mathrm{SBRr}$ aumentaram em relação ao poliestireno, elevando sua viscosidade. $O$ aumento da viscosidade das blendas binárias pode ser atribuída a presença de $50 \%$ de resíduos de elastômeros (SBRr) vulcanizado em pó, que atua como carga, provocando um aumento na viscosidade das blendas. Entre as blendas binárias com diferentes granulometrias de resíduo, praticamente não existem diferenças de torque entre si.

A Figura $2 b$ apresenta as curvas de reometria de torque do poliestireno e das blendas ternárias $\mathrm{PS} / \mathrm{SBRr} / \mathrm{SBS}$, variando-se a granulometria do $\mathrm{SBRr}$ e, mantendo-se constante $5 \%$ em peso do compatibilizante SBS. Observa-se que os valores dos torques das blendas ternárias PS/SBRr/SBS (18) e (40) foram maiores do que a do poliestireno. Constata-se ainda, que o torque final da blenda PS/SBRr/SBS ( I8) ficou no mesmo patamar das blendas binárias. Porém, a blenda PS/SBRr/SBS (40) tendeu a um maior torque quando comparada com as blendas binárias, provavelmente devido a sua menor granulometria, aliada à contribuição do SBS que apresenta baixo índice de fluidez. Além disso, possíveis interações podem ter ocorrido entre os grupos químicos similares, como os blocos de estireno do SBS e as moléculas do PS e do SBRr. Nota-se ainda na Figura $2 \mathrm{~b}$ que a blenda PS/SBRr/SBS (40) apresentou uma viscosidade levemente superior à blenda $\mathrm{PS} / \mathrm{SBRr} / \mathrm{SBS}$ ( 18 ). A maior viscosidade daquela blenda pode ser consequência de uma maior ocorrência de processos de entrecruzamentos de cadeias, bem como, devido ao menor tamanho de partícula das cargas que pode conduzir ao aumento da viscosidade dos compostos poliméricos. Observa-se no geral que o PS apresentou menor valor de torque, ou seja, apresentou uma viscosidade mais baixa quando comparado com as blendas binárias e ternárias em ambas as granulometrias de SBRr. Isto pode indicar menor consumo de energia para seu processamento, apesar de ser um polímero viscoso com baixo índice de fluidez de $4,5 \mathrm{~g} / 10 \mathrm{~min}$.

\subsection{Propriedades Mecânicas}

A Tabela I e Figura $3(a, b)$ ilustram os resultados de resistência ao impacto e rigidez sob flexão para o PS, para as blendas binárias e ternárias preparadas com $5 \%$ de compatibilizante e diferente granulometrias do SBRr.

A Tabela I e Figura 3a evidenciam que o PS apresentou a mais baixa resistência ao impacto, em torno de $24 \mathrm{~J} / \mathrm{m}$. O PS pode ser caracterizado como um material rígido, porém frágil o que é confirmado pela baixa resistência ao impacto. Observa-se que a adição de um material tenaz e flexível (resíduo de borracha) a uma matriz rígida e amorfa (PS) provoca aumento na resistência ao impacto. Nota-se que independente da granulometria, a resistência ao impacto aumentou substancialmente em relação à matriz de PS, e este aumento foi mais pronunciado para as blendas compatibilizadas com $5 \%$ em massa de SBS. As blendas binárias
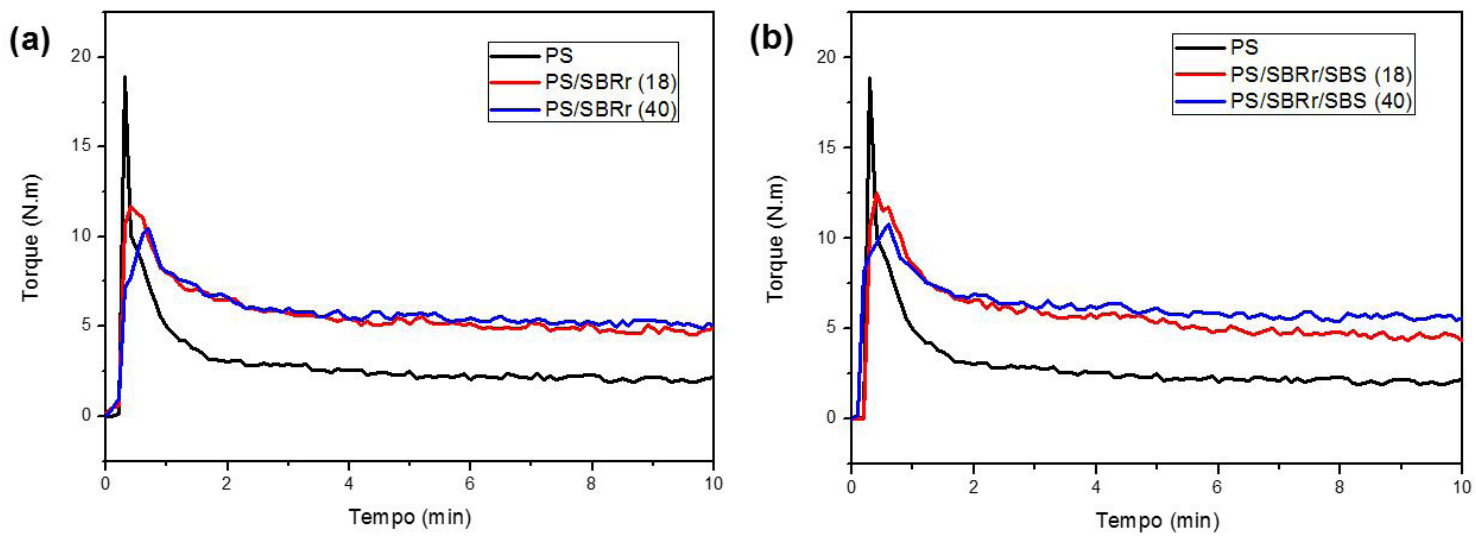

Figura 2. Curvas de torque em função do tempo para amostras de PS, blendas binárias e ternárias com diferentes granulometrias, respectivamente. 
$\mathrm{PS} / \mathrm{SBRr}$ com granulometrias de 18 e 40 mesh aumentaram em 125 e $133 \%$ a resistência ao impacto em relação ao PS, respectivamente. Estes aumentos possivelmente podem ser atribuídos à capacidade das partículas de borracha, que quando embebidas em polímeros vítreos e submetidas ao campo de tensões associadas a uma trinca que se propaga, de deformarem e cavitarem absorvendo energia de deformação elástica e plástica durante o processo de fratura [14].

De acordo com a Tabela I, nota-se que as blendas $\mathrm{PS} / \mathrm{SBRr} / \mathrm{SBS}$ com ambas as granulometrias aumentaram de forma expressiva a resistência ao impacto em relação ao PS e as blendas binárias, mostrando assim que são interessantes do ponto de vista tecnológico para aplicações industriais. Então, provavelmente o SBS aumentou a interação entre o poliestireno e o resíduo de borracha (SBRr), promovendo uma maior adesão entre os contornos das fases facilitando a transferência de tensões [15]. De acordo com a Tabela I para as faixas de granulometrias investigadas, partículas de borracha passantes na peneira 40 mesh apresentaram melhores resultados em relação às partículas passadas na peneira 18 mesh, sendo a maior influência para as blendas compatibilizadas. Observa-se que para as blendas binárias $\mathrm{PS} / \mathrm{SBRr}$ não há diferença estatística entre os resultados de resistência ao impacto para as duas granulometrias, porém, para as blendas ternárias a diferença está no limite dos desvios padrões. Entretanto, pode-se sugerir que as partículas de borracha menores promovem uma melhor distribuição das tensões internas e, como consequência

Tabela I. Módulo de elasticidade sob flexão e resistência ao impacto Izod dos materiais

\begin{tabular}{lcc}
\hline Materiais & $\begin{array}{c}\text { Resistência ao } \\
\text { impacto (J/m) }\end{array}$ & $\begin{array}{c}\text { Módulo de } \\
\text { Elasticidade sob } \\
\text { Flexão (MPa) }\end{array}$ \\
\hline PS & $24 \pm 2,0$ & $1323 \pm 35$ \\
PS/SBRr (40) & $56 \pm 4,3$ & $365 \pm 20$ \\
PS/SBRr (I8) & $54 \pm 3,9$ & $250 \pm 22$ \\
PS/SBRr/SBS (40) & $85 \pm 3,7$ & $1191 \pm 27$ \\
PS/SBRr/SBS (18) & $78 \pm 3,9$ & $500 \pm 18$ \\
\hline
\end{tabular}

um aumento na área superficial das fissuras [16]. Tal fato corrobora com os resultados de resistência ao impacto, onde as partículas de menor granulometria apresentam uma maior área superficial e, consequentemente, distribuiu melhor as tensões.

Conforme Figura 3b e Tabela I, o PS apresenta o valor mais alto de módulo de elasticidade sob flexão. Isto pode ser atribuído à estrutura química do PS que não possui butadieno em sua cadeia, o qual confere flexibilidade ao polímero [17]. Observa-se no geral que a introdução de uma fase elastomérica na matriz rígida de PS, promove uma diminuição no valor do módulo de elasticidade independente se a blenda é compatibilizada ou não. Portanto, pode-se inferir que as blendas tenacificadas deformam-se em tensões menores que a do PS.

$\mathrm{Na}$ Figura 3b, independente da granulometria de SBRr, a presença de $50 \%$ de SBRr nas blendas binárias, alterou drasticamente as propriedades do módulo de elasticidade sob flexão em relação a matriz de PS. Como os elastômeros possuem baixo módulo, o elevado teor de elastômero nas misturas promoveu uma queda do módulo sob flexão [18]. Por outro lado, quando se considera que trata-se de um resíduo de borracha, constituído de uma mistura complexa de $\mathrm{SBRr}$ (copolímero de estireno-butadieno), cargas, aditivos de processamento, agentes de cura e estabilizantes, supõem-se que pode ter prejudicado a adesão entre as partículas de borracha e a matriz de PS.

Como reportado por Lievana e Kocsis [19] a adesão entre resíduo de borracha e a matriz polimérica é muito baixa, devido à estrutura de ligações cruzadas da borracha que dificulta o emaranhamento entre as moléculas.

De acordo com a Figura 3b, a blenda PS/SBRr/SBS (40) foi a que apresentou o melhor resultado do módulo de elasticidade sob flexão, provavelmente devido a influência da ação interfacial do compatibilizante, aumentando a adesão entre as fases. Essa maior adesão na interface foi favorecida pela maior área superficial das partículas e, consequentemente, promoveu uma maior interação entre o PS e o SBRr. O valor observado para esta blenda é muito interessante do ponto de vista tecnológico, pois a mesma
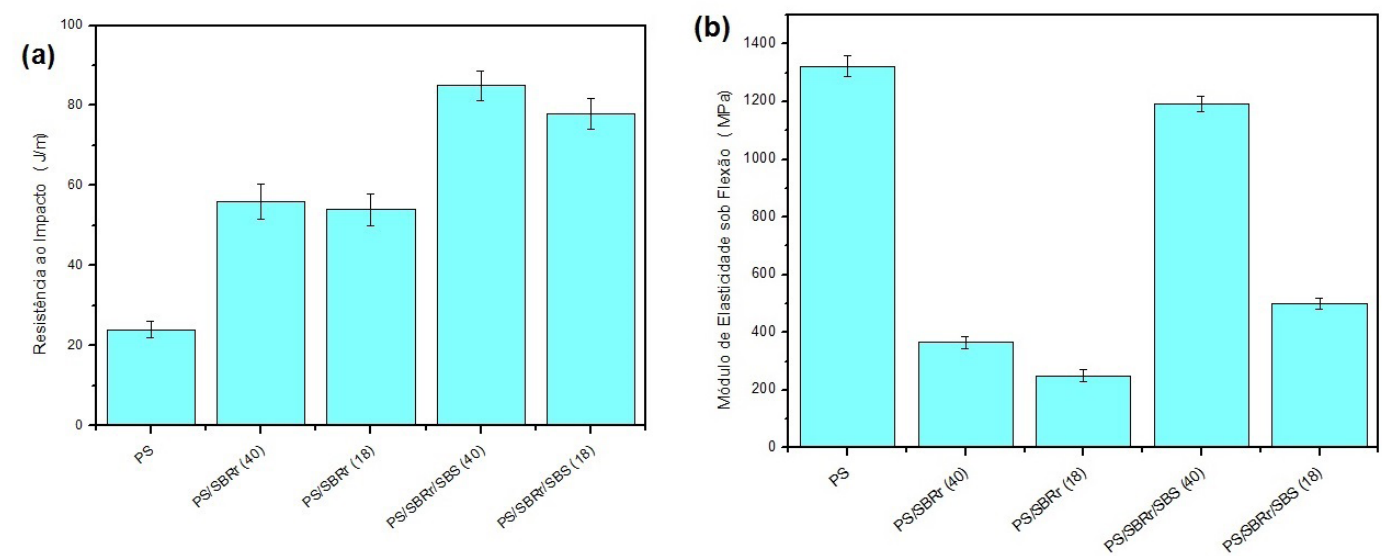

Figura 3. Propriedades mecânicas de resistência ao impacto e módulo de elasticidade sob flexão dos materiais. 
teve um aumento de $254 \%$ de resistência ao impacto em relação ao PS, bem como uma perda de apenas $10 \%$ no valor da rigidez.

\subsection{Temperatura de Deflexão Térmica (HDT)}

O ensaio de temperatura de deflexão térmica é de extrema importância para os polímeros, pois trata-se de uma técnica muito utilizada em peças na indústria automobilística. A Tabela 2 apresenta os dados obtidos para a temperatura de deflexão térmica do PS, das blendas binárias e ternárias, bem como a tendência destas com as diferentes granulometrias do SBRr e o efeito do compatibilizante.

Observa-se na Tabela 2 que a HDT do PS ficou na faixa de $80^{\circ} \mathrm{C}$, e houve uma queda da HDT das blendas compatibilizadas e sem compatibilizante em relação à matriz de PS. Este alto valor da HDT do PS, provavelmente pode ser atribuído ao fato deste polímero ser caracterizado como um material rígido e, possivelmente necessitando de uma maior temperatura para que o corpo de prova sofra deflexão.

Tabela 2. Temperatura de deflexão térmica do PS, das blendas binárias e ternárias

\begin{tabular}{lc}
\hline \multicolumn{1}{c}{ Materiais } & $\begin{array}{c}\text { Temperatura de Deflexão } \\
\text { Térmica }\left({ }^{\circ} \mathbf{C}\right)\end{array}$ \\
\hline PS & $80 \pm 2,2$ \\
PS/SBRr (40) & $66 \pm 1,8$ \\
PS/SBRr (18) & $63 \pm 3,9$ \\
PS/SBRr/SBS (40) & $67 \pm 3,7$ \\
PS/SBRr/SBS (18) & $63 \pm 3,9$ \\
\hline
\end{tabular}

$\mathrm{Na}$ Tabela 2 nota-se que a adição de SBRr ao PS diminuiu a HDT de todas as blendas. Tal fato é atribuído ao SBRr, por se tratar de um elastômero que apresenta alta flexibilidade, devido ao seu alto valor de butadieno (>70\%) [20], e consequentemente atua tornando o sistema $\mathrm{PS} / \mathrm{SBRr}$ mais flexível, gerando perda no comportamento da HDT.

A temperatura de deflexão térmica não sofre influência com a variação da maioria das variáveis, mas somente com o aumento do teor de borracha [2I]. Portanto, possivelmente o alto teor de borracha incorporada nas blendas de PS/SBRr foi o fator preponderante para perda desta propriedade. Por outro lado, observa-se na Tabela 2 que a granulometria do SBRre o compatibilizante não afetaram de forma significativa esta propriedade. Nota-se que as blendas binárias e ternárias com ambas granulometrias oscilaram de forma mínima, ou seja, não houve perda de propriedade de forma significativa entre as blendas produzidas. Entretanto, novamente é importante enfatizar que a blenda PS/SBRr/SBS (40) apresentou o melhor resultado.

\subsection{Microscopia Eletrônica de Varredura}

A Figura 4 evidencia as micrografias obtidas por MEV das blendas binárias e ternárias com as respectivas granulometrias do SBRr. Estas micrografias foram obtidas da superfície de fratura dos corpos de prova das blendas binárias e ternárias, submetidas ao ensaio de impacto lzod.

Nas Figuras 4a,b pode-se observar espaços vazios entre as fases (setas vermelhas), o que indica uma fraca adesão entre a fase dispersa e a fase contínua, caracterizando
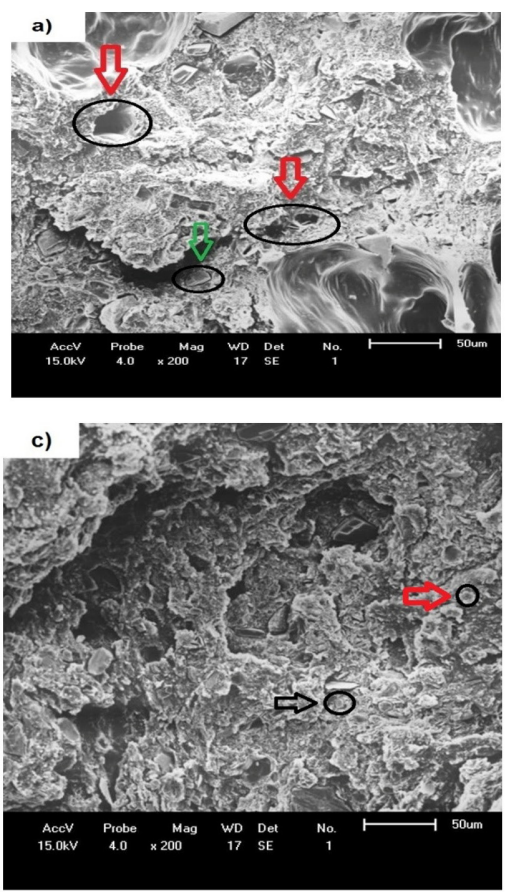
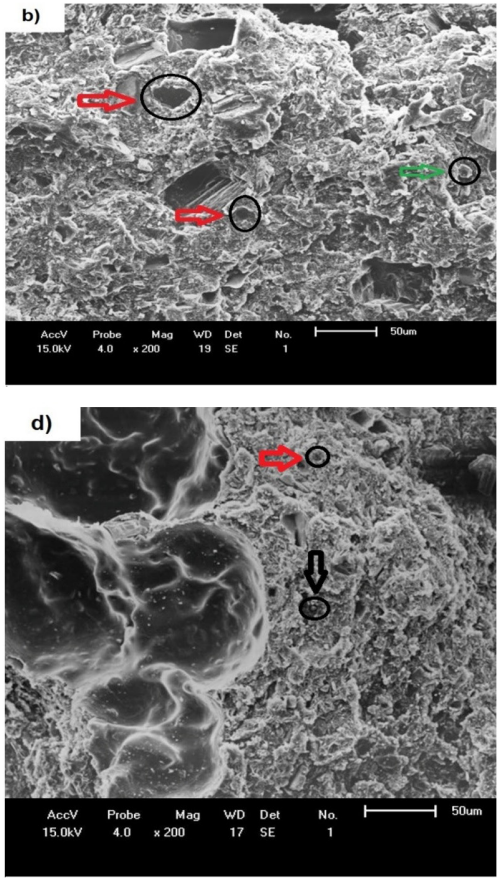

Figura 4. Micrografias obtidas por MEV das blendas binárias e ternárias: (a) PS/SBRr (I8); (b) PS/SBRr (40); (c) PS/SBRr/SBS (I8); (d) PS/SBRr/ SBS (40). 
um sistema incompatível. A má adesão ocorre devido à alta tensão interfacial existente entre os componentes, o que torna a interface com baixa resistência [22]. De fato, como pode ser verificado na Figura 4a,b, várias partículas foram sacadas totalmente da matriz durante a fratura do corpo de prova. Pode-se verificar que os vazios deixados nas blendas $\mathrm{PS} / \mathrm{SBRr}$ são de tamanhos diferentes. Aparentemente, para as Figuras $4 a, b$ não se observa grandes diferenças entre si na morfologia desses sistemas, bem como não se evidencia diferenças significativas de tamanhos entre as partículas de borracha (setas verdes). Por isso, provavelmente não se observou uma diferença significativa na resistência ao impacto destas blendas. Além disso, a incompatibilidade entre a matriz e a fase dispersa, visualizada por meio da morfologia $4(a, b)$, corrobora os resultados das propriedades mecânicas desses sistemas, que foram inferiores às dos sistemas compatibilizados.

As Figuras 4c,d ilustram as superfícies de fratura das blendas PS/SBRr/SBS compatibilizadas com $5 \%$ em massa de SBS e diferentes granulometrias de SBRr. Pode ser observado claramente que ocorreu uma elevada redução no tamanho das partículas dispersas (setas pretas) nas blendas, principalmente para a mistura PS/SBRr/SBS (40). Esse efeito pode acontecer devido à difusão e habilidade do compatibilizante em permanecer na interface entre as fases dos constituintes, promovendo uma redução da energia interfacial e evitando o coalescimento das partículas [23]. A redução do tamanho da fase dispersa dentro de certo limite é importante no resultado final, pois aumenta a área interfacial e melhora a transferência de tensões impostas ao sistema [24]. Verifica-se também, que a adição do compatibilizante promoveu uma maior adesão interfacial (setas vermelhas), e consequentemente elevando a resistência ao impacto das blendas, como pode ser verificado na Tabela I.

\section{CONCLUSÕES}

Blendas de PS/resíduo de calçados (SBRr), com diferentes granulometrias e, compatibilizadas com SBS foram obtidas. A resistência ao impacto tanto para as blendas binárias quanto para as ternárias aumentou expressivamente em relação ao PS, e este aumento foi mais pronunciado para as blendas ternárias, indicando o efeito positivo do compatibilizante SBS. O módulo de elasticidade sob flexão e a temperatura de deflexão térmica diminuíram com a incorporação do SBRr. As fotomicrografias evidenciaram que as blendas compatibilizadas apresentaram morfologia mais estável, uma vez que promoveu uma maior adesão interfacial entre o PS e o SBRr. A granulometria tem maior influência na resistência ao impacto e praticamente não afetou a temperatura de deflexão térmica. A blenda ternária PS/SBRr/SBS (40) apresentou a melhor relação de propriedades de tenacidade/rigidez, bem como pouca perda da HDT. O perfil das curvas de reometria das blendas praticamente não apresentou mudanças significativas, ou seja, a granulometria do SBRr afetou pouco a viscosidade do sistema, porém a incorporação destes resíduos em pó ao $\mathrm{PS}$ aumentou a viscosidade quando comparada à matriz pura. O resíduo de calçado de borracha mostra-se eficaz no processo de tenacificação do PS, bem como pode reduzir o custo do composto final e minimizar os efeitos desse rejeito sobre o meio ambiente.

\section{Agradecimentos}

Os autores agradecem à CAPES (Coordenação de Aperfeiçoamento de Pessoal de Nível Superior) pela concessão de bolsa de estudo do doutorado, ao PIBIC, a São Paulo Alpargatas/PB pelo fornecimento de matéria prima, à Kraton Polymers do Brasil, ao PNPD/CAPES e ao $\mathrm{MCTI} / \mathrm{CNPq}$ pelo apoio financeiro.

\section{REFERÊNCIAS}

I Figueiredo AL, Alves APM, Fernandes VJ Jr, Araújo AS. Reciclagem terciária do poli(etileno tereftalato) visando a obtenção de produtos químicos e combustível: uma revisão. Revista Virtual de Química. 2015;7(4): I |45-I 162. http://dx.doi.org//0.5935/1984-6835.20150064.

2 Luna CBB, Silva DF, Basílio SKT, Araújo EM, Silva AL, Bezerra AFC. Desenvolvimento de blendas poliméricas visando a tenacificação dos polímeros: uma revisão. Semina: Ciências Exatas e Tecnológicas. 20I5;36(I):67-80. http://dx.doi.org/I0.5433/1679-0375.2015v36n I p67.

3 Araújo EM, Carvalho LH, Fook MVL, D’almeida JRM. Propriedades mecânicas de blendas de PS/resíduo de borracha: influência da concentração, granulometria e método de moldagem. Polímeros: Ciência e Tecnologia. 1997;7(3):45-52. http://dx.doi.org/I0.1590/S0 104-I428/997000300008.

4 Weber T, Zanchet A, Brandalise RN, Crespo JS, Nunes RCR. Grinding and characterization of scrap rubbers powders. Journal of Elastomers and Plastics. 2008;40(2): I47-I59. http://dx.doi.org/I0. I I 77/0095244307082487.

5 Fuhrmann I, Kocsis-Karger J. Kaiserlauter. Einfluß von altgummipartikeln auf das mechanische eigenschaftsprofil von thermoplast-blends. Kautschuk, Gummi, Kunststoffe. 1999;52(12):836-84I.

6 Zhang J, Chen H, Zhou Y, Ke C, Lu H. Compatibility of waste rubber powder/polystyrene blends by the addition of styrene grafted styrene butadiene rubber copolymer: effect on morphology and properties. Polymer Bulletin. 2013;70(I0):2829-284I. http://dx.doi.org//0.1007/s00289-0I3-099I-3. 
7 Becker D. Blendas de PP/PU: estudo do efeito do agente compatibilizante e reciclagem de resíduos de PU [dissertação de mestrado]. Santa Catarina: Universidade Federal de Santa Catarina; 2002.

8 Qin J, Argon AS, Cohen RE. Toughening of glassy polystyrene through ternary blending that combines low molecular weight polybutadiene diluents and ABS or HIPS-type composite particles. Journal of Applied Polymer Science. 1999;7I(I4):2319-2328. http://dx.doi.org/I0.1002/(SICl) 1097-4628(I9990404)7I:I4<23 I9::AIDAPP5 > 3.0.CO;2-I.

9 Zhao J, Wei D, Wang Z. Thermoplastic elastomers based on high-impact polystyrene/waste styrene butadiene rubber powder blends enhanced by styrene-butadiene-styrene block copolymer and aromatic oil. Journal of Macromolecular Science, Part B: Physics. 2015;54(3):262-274. http://dx.doi.org/10.1080/00222348.20I4.1000739.

10 Gopalakrishnan J, Kutty SKN. Mechanical, thermal, and rheological properties of dynamically vulcanized natural rubber-toughened polystyrene. Journal of Elastomers and Plastics. 20I5;47(2):153-169. http://dx.doi. org/ I 0. I I77/00952443 I3507802.

I I Luna CBB, Silva DF, Araújo EM. Análise do comportamento termomecânico, térmico e mecânico de blendas de PA6/resíduos de borracha. Revista de Engenharia e Tecnologia. 2014;6(I):I60-169.

12 Weber T, Oliveira MG, Zeni M, Crespo JS, Nunes RCR. Processability of revulcanizable SBR compositions. Polymer Bulletin. 2008;6I(2):2 I7-224. http://dx.doi.org//0.1007/s00289-008-0937-3.

13 Serrano CLR. Uso de resíduos de SBR proveniente da indústria de calçados em composição de SBR [tese de doutorado]. Porto Alegre: Universidade Federal do Rio Grande do Sul; 2009.

14 Mathur D, Nauman EB. Impact strength of bulk PS/PB blends: compatibilization and fracture studies. Journal of Applied Polymer Science. 1999;72(9): I I5I-I I64. http://dx.doi.org/ 10.1002/(SICl) I0974628(I999053I)72:9<| I5I ::AID-APP5 > 3.0.CO;2-6.

15 Wu J, Guo B, Chang CM, Li J, Tang HS. Synergistic toughening effect of SBS and HDPE on the fracture of the PS/ HDPE/SBS blends. Polymer. 200 I;42(2I):8857-8865. http://dx.doi.org/10.1016/S0032-386 I (01)00443-8.

16 Yokouchi M, Yokota A, Kobayashi Y. Tensile and impact behavior of drawn polystyrene and high-impact polystyrene. Journal of Applied Polymer Science. 1982;27(8):3007-30 I8. http://dx.doi.org/10.1002/app. 1982.070270824.

17 Guerrero LR, Keskkula H, Paul DR. Deformation processes in high Impact polystyrene as revealed by analysis of arrested cracks. Polymer. 2000;4I(I4):54I5-542I. http://dx.doi.org/I0.1016/S0032-386I(99)00725-9.

18 Coutinho FMB, Costa MPM, Guimarães MJOC, Soares BG. Preparation and characterization of high-impact polystyrene using different types of polybutadiene. Journal of Applied Polymer Science. 2008; 108(I):406-4I3. http:// dx.doi.org/10.1002/app.27656.

19 Lievana EJ, Kocsis JK. Use of ground tyre rubber (GTR) in thermoplastic polyolefin elastomer compositions. Progress in Rubber, Plastics and Recycling Technology. 2004;20(I): I-I0.

20 Grison EC, Becker E, Sartori A. Borrachas e seus aditivos: componentes, influência e segredos. I. ed. Porto Alegre: Suliani; 2010.

2I Grassi VG, Forte MMC, Pizzol MFD. Aspectos morfológicos e relação estrutura-propriedades de poliestireno de alto impacto. Polímeros: Ciência e Tecnologia. 200 I; I (3):I58- I68. http://dx.doi.org/I0.1590/S0 I0414282001000300016.

22 Joseph S, Lauprêtre F, Negrell C, Thomas S. Compatibilising action of random and triblock copolymers of poly(styrene-butadiene) in polystyrene/polybutadiene blends: a study by electron microscopy, solid state nmr spectroscopy and mechanical measurements. Polymer. 2005;46(22):9385-9395. http://dx.doi.org/10.1016/j. polymer.2005.07.053.

23 Cavanaugh TJ, Buttle K, Turner JN, Nauman EB. The study of various styrene-butadiene copolymers as compatibilisers in bulk blends of polystyrene/polybutadiene. Polymer. 1998;39(I8):4|9|-4I97. http://dx.doi. org/10.1016/S0032-386 I(98)00058-5.

24 Adhikari R, Michler GH. Influence of molecular architecture on morphology and micromechanical behavior of styrene/butadiene block copolymer systems. Progress in Polymer Science. 2004;29(9):949-986. http://dx.doi. org/10.1016/j.progpolymsci.2004.06.002.

Recebido em: 10 Mar. 2016

Aceito em: 10 Nov. 2016 